\title{
Función predictiva del índice de neutrófilos/linfocitos y del volumen plaquetario medio en la púrpura de Henoch-Schönlein relacionada con compromiso renal y gastrointestinal
}

\author{
Predictive role of neutrophil to lymphocyte ratio and mean platelet volume in \\ Henoch-Schönlein purpura related gastrointestinal and renal involvement
}

\author{
Dr. Halil I. Yakut ${ }^{a}$, Dra. Tuba Kurt ${ }^{b}$ Dra. Nermin Uncu ${ }^{b}$, Dra. F. Semsa Caycic y Dra. Banu Celikel Acar ${ }^{b}$
}

\begin{abstract}
RESUMEN
Antecedentes: La púrpura de Henoch-Schönlein (PHS) es una vasculitis sistémica de vasos pequeños. El objetivo fue evaluar el índice de neutrófilos / linfocitos (INL) en sangre y el volumen plaquetario medio (VPM) en la PHS e investigar la relación con el compromiso renal y gastrointestinal.

Métodos: Se incluyeron niños con PHS y controles sanos. Se evaluaron concentración de hemoglobina, recuento de leucocitos, recuento de trombocitos, INL, VPM, velocidad de sedimentación globular y proteína C-reactiva.

Resultados: El INL fue significativamente mayor en los pacientes con PHS con hemorragia gastrointestinal $(p<0,001)$. El valor ideal de corte del INL para predecir la hemorragia gastrointestinal fue 2,05, con $93 \%$ de sensibilidad y $62 \%$ de especificidad. El VPM fue significativamente mayor en los pacientes con PHS con compromiso renal $(p=0,027)$.

Conclusiones: El INL en sangre y el VPM podrían ser útiles para identificar el compromiso renal y gastrointestinal en la PHS. Palabras clave: índice de neutrófilos/linfocitos en sangre, hemorragia gastrointestinal, púrpura de Henoch-Schönlein, volumen plaquetario medio, nefropatía.
\end{abstract}

http:/ / dx.doi.org/10.5546/aap.2020.139

Texto completo en inglés:

http:/ / dx.doi.org/10.5546/ aap.2020.eng.139

Cómo citar: Yakut HI, Kurt T, Uncu N, Cayci FS, Celikel Acar B. Función predictiva del índice de neutrófilos/linfocitos y del volumen plaquetario medio en la púrpura de Henoch-Schönlein relacionada con compromiso renal y gastrointestinal. Arch Argent Pediatr 2020;118(2):139-142.

\footnotetext{
a. Departamento de Pediatría.

b. Departamento de Reumatología Pediátrica.

c. Departamento de Nefrología Pediátrica.

Universidad de Ciencias de la Salud, Hospital de la Ciudad de Angora, Ankara, Turquía.
}

\section{Correspondencia:}

Dra. Banu Celikel Acar: banuacar@gmail.com

Financiamiento: Ninguno.

Conflicto de intereses: Ninguno que declarar.

Recibido: 29-5-2019

Aceptado: 23-9-2019

\section{INTRODUCCIÓN}

La púrpura de Henoch-Schönlein (PHS) es la vasculitis sistémica de vasos pequeños más frecuente en los niños. En general, el pronóstico de la PHS en los niños es favorable, pero incluye complicaciones graves, como compromiso gastrointestinal (GI) grave en la etapa inicial de la enfermedad. ${ }^{1,2}$

La morbilidad a largo plazo de la PHS se relaciona con el grado de compromiso renal. ${ }^{3-5}$ Por lo tanto, es importante evaluar los factores de riesgo de compromiso renal en los niños con PHS.

Se investigó el índice de neutrófilos / linfocitos (INL) en sangre en muchas enfermedades como marcador de inflamación. ${ }^{6-8}$ En pocos estudios sobre la PHS, se informó la asociación del INL con la hemorragia GI debido a la inflamación dominada por neutrófilos en los casos de PHS. Además, algunos informes indican que un volumen plaquetario medio (VPM) bajo también está relacionado con la gravedad del compromiso GI. ${ }^{9}$ El INL y el VPM se identifican como marcadores potencialmente útiles del compromiso GI en la etapa inicial de la enfermedad.

El objetivo de este estudio fue investigar la relación entre el INL y el VPM con el compromiso GI y renal en los casos de PHS, que determina el pronóstico del seguimiento a largo plazo.

\section{PACIENTES Y MÉTODOS}

Se revisó a todos los pacientes diagnosticados con PHS entre enero de 2015 y 2018 en nuestro centro. En el estudio, se incluyeron los pacientes pediátricos diagnosticados con PHS y niños sanos. Para definir la enfermedad, se emplearon los criterios diagnósticos de PHS de la Liga Europea contra el Reumatismo/la Sociedad Europea de Reumatología Pediátrica (European League against Rheumatism/Paediatric Rheumatology European Society, EULAR/PRES). ${ }^{10}$ Se seleccionó un grupo de referencia formado por niños sanos 
del mismo sexo y la misma edad que asistieron a los consultorios pediátricos de nuestro hospital por otros motivos.

Los criterios de exclusión fueron los siguientes: [1] presencia de enfermedades preexistentes; [2] uso de medicamentos antes de la obtención de la muestra de sangre; [3] falta de datos de laboratorio; [4] presencia de factores de riesgo (tabaquismo, obesidad, hipertensión, diabetes mellitus, etc.) que pudieran afectar el resultado del VPM.

Se registraron los datos demográficos, los signos y síntomas de la enfermedad y los datos de laboratorio en la base de datos electrónica al momento del diagnóstico. El INL se calculó como el índice simple entre el recuento absoluto de neutrófilos y el recuento absoluto de linfocitos. Se emplearon los resultados de laboratorio obtenidos al momento del ingreso (una semana después de la presentación).

La hemorragia gastrointestinal se definió como sangre oculta en heces, melena o rectorragia. El compromiso renal se definió como la presencia de hematuria ( $>5$ eritrocitos por campo microscópico) o proteinuria (índice proteína/creatinina en orina $<0,2$ en los niños $\geq 2$ años de edad).

El estudio recibió la aprobación ética del comité de ética local del hospital (2019/20), y se obtuvo el consentimiento informado de todos los pacientes.

\section{Análisis estadístico}

Todos los datos se analizaron con el paquete estadístico para ciencias sociales (Statistical Package for Social Sciences), versión 17.0 (SPSS, Inc. Chicago, Illinois, EE. UU.) para Windows. Las variables cuantitativas se expresaron como media \pm DE para los datos con distribución normal y como mediana (IIC) para aquellos sin distribución normal. Los datos cuantitativos de los grupos dobles se compararon con la prueba $t$ de Student o la prueba de la U de Mann-Whitney, según correspondiera, mientras que se realizó una prueba de $\chi^{2}$ para los datos cualitativos. Se hizo una regresión logística escalonada hacia atrás para determinar las variables asociadas con la hemorragia GI y el compromiso renal en los pacientes con PHS. Se usó una curva ROC para determinar la asociación del INL con la hemorragia GI en la PHS; un valor de $p \leq 0,05$ se consideró significativo.

\section{RESULTADOS}

El grupo de pacientes incluyó a 71 participantes: $41(57,7 \%)$ varones y $30(42,3 \%)$ niñas con PHS. El grupo de referencia incluyó a $38(51,3 \%)$ varones y $36(48,7 \%)$ niñas. Según los análisis estadísticos, la distribución por sexo entre los grupos fue similar $(p=0,506)$. La media de edad de los pacientes con PHS era de $8,7 \pm 3,6$ años y de los controles, $9,1 \pm 3,7$ años $(p=0,472)$.

Todos los pacientes presentaban púrpura palpable; $58(81,6 \%)$, artritis o artralgia; y $49(69 \%)$, compromiso GI; de estos, $16(22,5 \%)$ tenían hemorragia GI. Dos pacientes presentaron invaginación intestinal; 22 (30,9\%), compromiso renal; de estos, 13 pacientes $(18,3 \%)$ tenían proteinuria y $9(12,6 \%)$, proteinuria en rango nefrótico. Al principio, se observaron diferencias significativas entre los pacientes con PHS y los controles sanos en términos de recuento de leucocitos, recuento de trombocitos, INL, VPM, velocidad de sedimentación globular (VSG) y prueba de la proteína C-reactiva (PCR) (Tabla 1).

Se dividió a los 49 pacientes con PHS y compromiso GI en dos grupos, según la presencia de hemorragia GI. Había 16 pacientes con hemorragia GI y 33, sin hemorragia GI. No se observaron diferencias significativas en relación

TABLA 1. Comparación de los parámetros de laboratorio entre los pacientes con púrpura de Henoch-Schönlein y los controles sanos

\begin{tabular}{lccc}
\hline Parámetro & $\begin{array}{c}\text { Pacientes con PHS } \\
(\mathbf{n}=\mathbf{7 1})\end{array}$ & $\begin{array}{c}\text { Controles sanos } \\
(\mathbf{n}=\mathbf{7 4}) \\
\text { media } \pm \text { DE }\end{array}$ & $\begin{array}{l}\text { media } \pm \text { DE } \\
\text { Valor } \boldsymbol{p}\end{array}$ \\
\hline $\mathrm{Hb}(\mathrm{g} / \mathrm{dl})$ & $13,0 \pm 1,0$ & $13,5 \pm 1,2$ & 0,129 \\
Leucocitos $(\mathrm{fl})$ & $12,1 \pm 4,7$ & $8,2 \pm 2,3$ & $<0,001$ \\
Trombocitos $\left(\mathrm{x} 10^{3} / \mu \mathrm{l}\right)$ & $393,8 \pm 110,4$ & $319,1 \pm 78,9$ & $<0,001$ \\
$\mathrm{INL}$ & $3,0 \pm 2,4$ & $1,9 \pm 1,8$ & $<0,001$ \\
VPM & $7,7 \pm 0,7$ & $7,9 \pm 0,8$ & $<0,001$ \\
VSG $(\mathrm{mm} / \mathrm{h})$ & $26,6 \pm 16,0$ & $10,6 \pm 5,7$ & $<0,001$ \\
PCR $(\mathrm{mg} / \mathrm{dl})$ & $2,2 \pm 2,7$ & $0,4 \pm 0,5$ & $<0,001$ \\
\hline
\end{tabular}

PHS: púrpura de Henoch-Schönlein, Hb: hemoglobina, INL: índice de neutrófilos/linfocitos, VPM: volumen plaquetario medio, VSG: velocidad de sedimentación globular, PCR: proteína C-reactiva. 
con el recuento de leucocitos y trombocitos, el VPM, la VSG y la concentración de PCR entre estos dos grupos. Sin embargo, el INL fue significativamente más alto en los pacientes con PHS y hemorragia GI que en aquellos sin hemorragia GI $(4,7 \pm 3,1$ frente a $2,5 \pm 2,0$; $p<0,001$ ) (Tabla 2).

Se hizo un análisis de regresión logística de leucocitos, trombocitos, VPM, INL, VSG y PCR para identificar los factores predictivos de hemorragia GI en los pacientes con PHS. El análisis mostró que solo el INL estaba asociado con hemorragia GI $(p<0,001)$. Se usó una curva ROC para definir los umbrales diagnósticos del INL para predecir la hemorragia GI en los pacientes con PHS. El área bajo la curva del INL fue de 0,798 (intervalo de confianza del $95 \%$ : 0,660,$92 ; p<0,001$ ) (Figura 1). El valor ideal de corte del INL para predecir la hemorragia GI fue 2,05, con una sensibilidad del $93 \%$ y una especificidad del $62 \%$. Cuando se seleccionó un valor de corte del INL de 2,8, la sensibilidad se redujo al $81 \%$ y la especificidad aumentó al $77 \%$.

Se dividió a los pacientes con PHS en dos grupos según la presencia de compromiso renal. Había 22 pacientes con compromiso renal y 49 , sin compromiso renal. No se observaron diferencias significativas en relación con el recuento de leucocitos y trombocitos, el INL, la VSG y la concentración de PCR entre estos dos grupos. Sin embargo, el VPM fue significativamente más alto en los pacientes con PHS y compromiso renal que en aquellos sin compromiso renal $(8,0 \pm 0,8$ frente a $7,5 \pm 0,7 ; p=0,027$ ) (Tabla 3 ).

FIgURA 1. Curva ROC del índice de neutrófilos/linfocitos para la hemorragia gastrointestinal en la púrpura de Henoch-Schönlein

\section{Curva ROC}

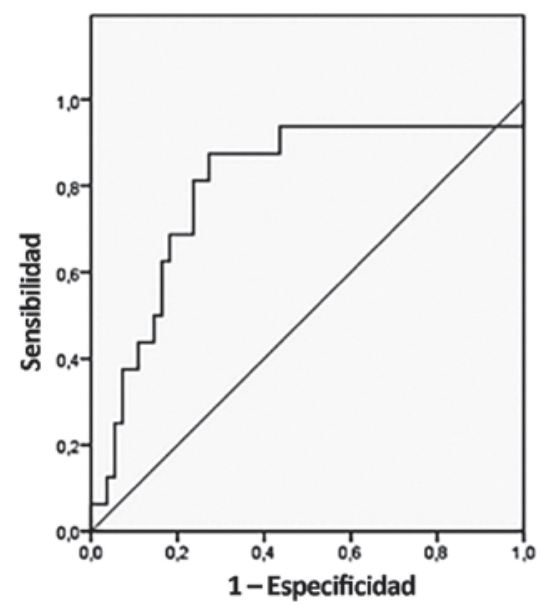

TABLA 2. Comparación de los parámetros de laboratorio entre los pacientes con y sin hemorragia gastrointestinal

\begin{tabular}{lccc}
\hline Parámetro & $\begin{array}{c}\text { Pacientes con hemorragia GI } \\
(\mathbf{n}=\mathbf{1 6}) \\
\text { media } \pm \text { DE }\end{array}$ & $\begin{array}{c}\text { Pacientes sin hemorragia GI } \\
(\mathbf{n}=\mathbf{3 3}) \\
\text { media } \pm \mathbf{D E}\end{array}$ & Valor $p$ \\
\hline $\mathrm{Hb}(\mathrm{g} / \mathrm{dl})$ & $12,4 \pm 0,9$ & $13,2 \pm 1,0$ & 0,002 \\
Leucocitos $(\mathrm{fl})$ & $12,7 \pm 4,0$ & $11,9 \pm 4,9$ & 0,198 \\
Trombocitos $\left(\mathrm{x} 10^{3} / \mu \mathrm{l}\right)$ & $404,4 \pm 116,4$ & $390,8 \pm 109,5$ & 0,625 \\
$\mathrm{INL}$ & $4,7 \pm 3,1$ & $2,5 \pm 2,0$ & $<0,001$ \\
$\mathrm{VPM}$ & $7,5 \pm 0,4$ & $7,7 \pm 0,8$ & 0,06 \\
VSG $(\mathrm{mm} / \mathrm{h})$ & $25,2 \pm 16,6$ & $27,0 \pm 3,2$ & 0,757 \\
$\mathrm{PCR}(\mathrm{mg} / \mathrm{dl})$ & $2,1 \pm 3,2$ & $2,2 \pm 2,6$ & 0,645 \\
\hline
\end{tabular}

GI: gastrointestinal, $\mathrm{Hb}$ : hemoglobina, INL: índice de neutrófilos/linfocitos, VPM: volumen plaquetario medio, VSG: velocidad de sedimentación globular, PCR: proteína C-reactiva.

TABLA 3. Comparación de los parámetros de laboratorio entre los pacientes con y sin compromiso renal

\begin{tabular}{|c|c|c|c|}
\hline Parámetro & $\begin{array}{c}\text { Pacientes con compromiso renal } \\
(\mathrm{n}=22) \\
\text { media } \pm \mathrm{DE} \\
\end{array}$ & $\begin{array}{c}\text { Pacientes sin compromiso renal } \\
(\mathrm{n}=49) \\
\text { media } \pm \mathrm{DE}\end{array}$ & Valor $p$ \\
\hline $\mathrm{Hb}(\mathrm{g} / \mathrm{dl})$ & $13,4 \pm 0,69$ & $12,9 \pm 1,2$ & 0,041 \\
\hline Leucocitos (fl) & $11,1 \pm 4,1$ & $12,5 \pm 4,9$ & 0,250 \\
\hline Trombocitos $\left(\times 10^{3} / \mu \mathrm{l}\right)$ & $361,8 \pm 82,7$ & $408,2 \pm 118,7$ & 0,129 \\
\hline INL & $2,8 \pm 2,2$ & $3,1 \pm 2,5$ & 0,467 \\
\hline VPM & $8,0 \pm 0,8$ & $7,5 \pm 0,7$ & 0,027 \\
\hline VSG (mm/h) & $28,5 \pm 19,7$ & $25,8 \pm 14,2$ & 0,746 \\
\hline PCR (mg/dl) & $2,4 \pm 3,0$ & $2,1 \pm 2,7$ & 0,623 \\
\hline
\end{tabular}

$\mathrm{Hb}$ : hemoglobina, INL: índice de neutrófilos / linfocitos, VPM: volumen plaquetario medio,

VSG: velocidad de sedimentación globular, PCR: proteína C-reactiva. 


\section{DISCUSIÓN}

La púrpura de Henoch-Schönlein es una vasculitis sistémica caracterizada por lesiones cutáneas purpúricas, manifestaciones gastrointestinales, artritis y compromiso renal. ${ }^{1,2}$ En muchos estudios, se sugirió que la trombocitosis, la leucocitosis, una VSG alta y una concentración elevada de PCR estaban asociadas con hemorragia GI en la PHS. ${ }^{5,11}$

En años recientes, se reveló que el VPM tiene una función real en los trastornos inflamatorios. Shi y cols., demostraron que los niños con PHS tenían un VPM más bajo que los individuos sanos. ${ }^{12}$ Makay y cols., revelaron que un VPM bajo podría estar relacionado con hemorragia GI en los casos de PHS. ${ }^{9}$ En algunos estudios, se sugirió que varias citocinas inflamatorias estaban elevadas en los pacientes con PHS y estas están relacionadas con la activación plaquetaria. Las citocinas inflamatorias activan los megacariocitos para que liberen más trombocitos de tamaño pequeño, por lo que un aumento en las citocinas inflamatorias podría producir una disminución del VPM. Otras investigaciones sugieren que los trombocitos grandes en las enfermedades inflamatorias graves se consumen a una mayor velocidad que los de tamaño pequeño en los sitios de inflamación. ${ }^{13,14}$ Como resultado, es inevitable que el VPM sea bajo para reflejar la gravedad de la inflamación. En nuestro estudio, si bien no fue posible determinar el valor de corte del VPM, se observó que este era más bajo en los pacientes con hemorragia GI que en aquellos sin hemorragia.

El INL se ha utilizado ampliamente para definir la gravedad de la inflamación..$^{6-8}$ La neutrofilia o linfopenia producen un INL alto, mientras que la linfocitosis o neutropenia ocasionan un INL bajo. Una de las manifestaciones histopatológicas características de la PHS es la infiltración celular neutrofílica. Los resultados de nuestro estudio demostraron que los pacientes con PHS y hemorragia GI tenían un INL significativamente más alto que aquellos sin hemorragia GI. En este estudio, el valor ideal de corte del INL para predecir la hemorragia GI fue 2,05, con una sensibilidad del $93 \%$ y una especificidad del $62 \%$. Se recomienda usar este valor de corte del INL para determinar qué pacientes con PHS podrían presentar hemorragia GI.

El compromiso renal se desarrolla en el transcurso de 4 a 6 semanas desde la aparición de la erupción, pero una insuficiencia renal terminal podría no ser evidente por varios años. Tener más de 7 años al momento de la aparición, síntomas abdominales graves, lesiones purpúricas persistentes y una disminución de la actividad del factor XIII se asocian con un aumento del riesgo de nefritis. ${ }^{15}$ Además de estos, se observó que un VPM bajo era un factor de riesgo de compromiso renal en nuestro estudio. Sin embargo, cabe recordar que el VPM por sí mismo, sin otras variables, podría no brindar información precisa para predecir la hemorragia GI en los niños con PHS.

Nuestro estudio presenta varias limitaciones. En primer lugar, debe considerarse que este estudio incluyó una muestra relativamente pequeña, en especial de pacientes con PHS y compromiso renal. En segundo lugar, el valor del VPM podría variar durante el curso de la PHS. Por último, este fue un estudio retrospectivo.

A modo de conclusión, se observó que el INL aumenta significativamente en la hemorragia GI. Además, un VPM más bajo estuvo asociado con compromiso renal en los pacientes con PHS. Por lo tanto, el INL y el VPM podrían ser marcadores útiles de la hemorragia GI y el compromiso renal en los pacientes con PHS.

\section{REFERENCIAS}

1. McCarthy HJ, Tizard EJ. Clinical practice: Diagnosis and management of Henoch-Schönlein purpura. Eur J Pediatr. 2010; 169(6):643-50.

2. Davin JC, Coppo R. Henoch-Schönlein purpura nephritis in children. Nat Rev Nephrol. 2014; 10(10):563-73.

3. Ronkainen J, Nuutinen M, Koskimies O. The adult kidney 24 years after childhood Henoch-Schönlein purpura: a retrospective cohort study. Lancet. 2002; 360(9334):666-70.

4. Stewart M, Savage JM, Bell B, McCord B. Long term renal prognosis of Henoch-Schönlein purpura in an unselected childhood population. Eur J Pediatr. 1988; 147(2):113-5.

5. LinSJ,HuangJL,HsiehKH.Clinical andlaboratory correlation of acute Henoch-Schönlein purpura in children. Zhonghua Min Guo Xiao Er Ke Yi Xue Hui Za Zhi. 1998; 39(2):94-8.

6. Uslu AU, Deveci K, Korkmaz S, Aydin B, etal. Is neutrophil/ lymphocyte ratio associated with subclinical inflammation and amyloidosis in patients with familial Mediterranean fever? Biomed Res Int. 2013; 2013:185317.

7. Kim JY, Park T, Jeong SH, Jeong CY, et al. Prognostic importance of baseline neutrophil to lymphocyte ratio in patients with advanced papillary thyroid carcinomas. Endocrine. 2013; 46(3):526-31.

8. O'Brien CE, Price ET. The blood neutrophil to lymphocyte ratio correlates with clinical status in children with cystic fibrosis: a retrospective study. PLoS One. 2013;8(10):e77420.

9. Makay B, Türkyilmaz Z, Duman M, Unsal E. Mean platelet volume in Henoch-Schönlein purpura: relationship to gastrointestinalbleeding. Clin Rheumatol. 2009;28(10):1225-8.

10. Ozen S, Ruperto N, Dillon MJ, Bagga A, et al. EULAR/ PReS endorsed consensus criteria for the classification of childhood vasculitides. Ann Rheum Dis. 2006; 65(7):936-41.

11. Chan H, Tang Y, Lv X, Zhang G, et al. Risk factors associated with renal involvement in childhood Henoch-Schönlein purpura: a meta-analysis. PLoS One. 2016; 11(11):e0167346.

12. Shi $X$, Li CW, Mo LJ, Li XH, et al. Altered mean platelet volume in children with Henoch-Schönlein purpura and its association with disease activity. Ann Clin Biochem. 2018; 55(3):368-72.

13. Ha TS. The role of tumor necrosis factor-alpha in HenochSchönlein purpura. Pediatr Nephrol. 2005; 20(2):149-53.

14. Kimura S, Takeuchi S, Soma Y, Kawakami T. Raised serum levels of interleukins 6 and 8 and antiphospholipid antibodies in an adult patient with Henoch-Schönlein purpura. Clin Exp Dermatol. 2013; 38(7):730-6.

15. de Almeida JL, Campos LM, Paim LB, Leone C, et al. Renal involvement in Henoch-Schönlein purpura: a multivariate analysis of initial prognostic factors. J Pediatr (Rio J). 2007; 83(3):259-66. 